\title{
Global carbon inequality
}

\author{
Klaus Hubacek ${ }^{1,2}$ - Giovanni Baiocchi ${ }^{1,8} \cdot$ Kuishuang Feng ${ }^{1} \cdot$ Raúl Muñoz Castillo $^{1,3}$ • \\ Laixiang Sun ${ }^{1,4,5} \cdot$ Jinjun Xue $\mathrm{e}^{6,7}$
}

\footnotetext{
${ }^{1}$ Department of Geographical Sciences, University of Maryland, College Park, MD, USA

2 Department of Environmental Studies, Masaryk University, Brno, Czech Republic

${ }^{3}$ Interamerican Development Bank, Washington, DC, USA

${ }^{4}$ SOAS, University of London, London, UK

${ }^{5}$ International Institute for Applied Systems Analysis (IIASA), Laxenburg, Austria

${ }^{6}$ Graduate School of Economics, Nagoya University, Nagoya 4648601, Japan

${ }^{7}$ Hubei University of Economics, Wuhan, China

${ }^{8}$ Department of Economics, University of Maryland, College Park, MD, USA
}

Received: 8 March 2017/Revised: 20 July 2017/Accepted: 25 July 2017 /Published online: 25 October 2017

(C) Joint Center on Global Change and Earth System Science of the University of Maryland and Beijing Normal University and Springer-Verlag GmbH Germany 2017

\begin{abstract}
Global climate change and inequality are inescapably linked both in terms of who contributes climate change and who suffers the consequences. This fact is also partly reflected in two United Nations (UN) processes: on the one hand, the Paris Agreement of the UN Framework Convention on Climate Change under which countries agreed to hold the increase in the global average temperature to below $2{ }^{\circ} \mathrm{C}$ above pre-industrial levels and, on the other hand, the UN's Sustainable Development Goals aiming to end poverty. These agreements are seen as important foundation to put the world nations on a sustainable pathway. However, how these agreements can be achieved or whether they are even mutually compatible is less clear. We explore the global carbon inequality between and within countries and the carbon implications of poverty alleviation by combining detailed consumer expenditure surveys for different income categories for a wide range of countries with an environmentally extended multi-regional input-output approach to estimate carbon footprints of different household groups, globally, and assess the carbon implications of moving the poorest people out of poverty. Given the current context, increasing income leads to increasing carbon footprints and makes global targets for mitigating greenhouse gases more difficult to achieve given
\end{abstract}

Electronic supplementary material The online version of this article (doi:10.1007/s40974-017-0072-9) contains supplementary material, which is available to authorized users.

Klaus Hubacek

hubacek@umd.edu the pace of technological progress and current levels of fossil fuel dependence. We conclude that the huge level of carbon inequality requires a critical discussion of undifferentiated income growth. Current carbon-intensive lifestyles and consumption patterns need to enter the climate discourse to a larger extent.

Keywords Poverty · Input-output analysis · Greenhouse gases - Mitigation - Lifestyles - Consumption patterns · Climate change

\section{Introduction}

In 2015, 195 countries signed the Paris Agreement of the United Nations (UN) Framework Convention on Climate Change, under which they agreed "...to strengthen the global response to the threat of climate change, in the context of sustainable development and efforts to eradicate poverty, including by holding the increase in the global average temperature to well below $2{ }^{\circ} \mathrm{C}$ above pre-industrial levels in the long term" (UNFCCC 2015). In the same vein, the new chair of the UN's Intergovernmental Panel on Climate Change (IPCC), Hoesung Lee, who is in charge of the next Climate Change Assessment Report, also stresses the importance of economic development and poverty reduction, when addressing climate change. At the same time, another important UN process culminated in countries agreeing to the Sustainable Development Goals (SDGs) with the aim of ending poverty and promoting sustainable growth, which are the two key items of the new 
sustainable development agenda adopted by the UN's General Assembly in September of 2015. These agreements are seen as an important foundation that is required to put the world economies on a sustainable pathway. However, how these agreements can be achieved or whether they are even mutually compatible is less clear. These issues must be considered within the context of global income and "carbon inequality" characterized by a historical responsibility with a small number of developed countries being responsible for most of cumulative greenhouse gas emissions (Baumert et al. 2005); current levels of resource extraction and throughput caused by a relatively small part of global population; and about three quarters of a billion people still living in extreme poverty (Motesharrei et al. 2016). The extent of inequality is expressed in stark terms by a recent Oxfam report. According to the report, the wealth of the world is divided into two: almost half is going to the richest $1 \%$; the other half to the remaining 99\% (Hardoon 2015). When looking at the extreme ends of the distribution, we find that the wealth possessed by the richest 80 individuals is equal to the wealth of the poorest half (i.e., about 3.7 billion people) of the global population (Hardoon 2015). While these estimates are not to be taken at face value, they do provide a powerful narrative about the extent of global inequality.

Over time, the global community has responded with numerous policy goals to address the issue of poverty. There has been a long history of high-level attempts such as the UN Conference on the Human-Environment in Stockholm (United Nations 1972), the Brundtland Report (World Commission on Environment and Development 1987), the Rio Declaration on Environment and Development (United Nations 1992), the Plan of Implementation of the World Summit on Sustainable Development in Johannesburg (United Nations 2002) and the Millennium Development Goals (United Nations 2002), for achieving poverty reduction. "End poverty in all its forms everywhere" is the first of the UN development goals as poverty eradication is seen as the greatest global challenge facing the world today (United Nations 2012). According to the Action Agenda for Sustainable Development, a report by the UN Council of the Sustainable Development Solutions Network, sustainable economic growth should allow all low-income countries to be able to reach the per capita income threshold of middle-income countries by 2030 . The goal of sustainable development goes beyond ending poverty. Sustainable development requires to meet the twin objective: to ensure that all people have the resources needed, such as food, water, access to health care and energy, to fulfill their human rights and to ensure that humanity's use of natural resources does not stress critical earth system processes (United Nations 2015); and this is where poverty alleviation meets climate mitigation.
As with poverty reduction, a number of high-level activities have been under way in the climate arena, accumulating in the targets set by the recent Paris agreement and earlier already by the Cancun UNFCCC meeting. Achieving the Paris climate target of staying within a $2{ }^{\circ} \mathrm{C}$ increase would require aggressive decarbonization in rich countries but is also seen as potentially limiting aspirations of poor countries given the fact that greenhouse gas emissions are highly coupled with economic growth and the climate target permits little room for fossil fuel-based energy growth (Steckel et al. 2013). Two broad approaches have been pursued hitherto in international negotiations: "top-down" international agreements, such as the so-called Kyoto Protocol, and "bottom-up" (voluntary) contributions by nations, cities, companies and other entities. The topdown approach has made little progress so far due to the open access problem of global atmospheric sinks and the associated free rider problem (Raupach et al. 2014), but the approach can nevertheless provide an important framework within which more ambitious voluntary contributions can take place. There are a number of ways of sharing emissions quota. Equity-focused approaches allocate emissions according to a country's historical or current responsibility in terms of (cumulative) contributions to greenhouse gas emissions. One variant of the equity-focused approach is the contraction and convergence argument which allocates emissions based on equal rights to pollute or utilize these commons for every individual (Baer et al. 2000). Such an approach requires knowledge about per capita carbon footprints across income groups and countries. In this study, we address this important issue. We will provide some groundwork for the ongoing discussion of greenhouse gas mitigation targets and a basis for allocating emission rights between countries taking inequalities between and within countries into account.

The key questions we try to address are as follows: What are the differences in carbon footprints for different income categories in different countries and globally? To address this question, we will assess the relative contribution to total carbon emissions of four global income categories and examine whether there is a convergence of consumption patterns and carbon footprints of people with increasing income across countries. These assessments enable us to develop scenarios and quantify the carbon implications of important likely or potential socioeconomic change so that we can answer the following questions: What are the carbon implications of moving hundreds of millions of people out of poverty? What are the carbon implications of urbanization and associated lifestyle and income changes in the two most populous countries, India and China, given current trends? For the above purposes, we present our compilation of consumption patterns for different income categories from consumer expenditure surveys for most 
countries of the world. We then link these consumption patterns to a global multi-regional input-output model and to calculate carbon footprints for different income categories, globally.

\section{Methods and data}

To compute household carbon footprints, we use multiregional input-output (MRIO) analysis. The MRIO-based approach enables us to calculate emissions and resource use along global supply chains (Wiedmann 2009). MRIO is based on national economic input-output tables depicting flows of money and embodied resources to and from sectors within and between countries. This approach has been applied to global environmental issues such as land use (Weinzettel et al. 2013; Yu et al. 2013), biodiversity (Lenzen et al. 2012a), water consumption (Feng et al. 2011), pollutants such as $\mathrm{SO}_{2}$ (Prell et al. 2014) and frequently to $\mathrm{CO}_{2}$ and other greenhouse gas (GHG) emissions (e.g., Prell and Feng 2016; Davis et al. 2011; Peters et al. 2011)

In a MRIO framework, different regions (countries in this research) are connected through inter-regional trade, $T^{r s}$ and $T^{s r}$. The technical coefficient sub-matrix $A^{r s}$ consisting of $\left\{a_{i j}^{r s}\right\}$ is given by $a_{i j}^{r s}=t_{i j}^{r s} / x_{j}^{s}$, in which $t_{i j}^{r s}$ is the inter-sector monetary flow from sector $i$ in region $r$ to sector $j$ in region $s ; x_{j}^{s}$ is the total output of sector $j$ in region $s$. The final demand matrix is $\left\{y_{i}^{r . f}\right\}$, where $y_{i}^{r . f}$ is the $f$ th category of final demand of region $r$ for goods of sector $i$. Using matrix notation and dropping the subscripts, we have

$$
\begin{gathered}
A=\left[\begin{array}{cccc}
A^{11} & A^{12} & \ldots & A^{1 R} \\
A^{21} & A^{22} & \cdots & A^{2 R} \\
\vdots & \vdots & \ddots & \vdots \\
A^{R 1} & A^{R 2} & \cdots & A^{R R}
\end{array}\right] ; \\
Y=\left[\begin{array}{cccc}
y^{1,1} & y^{1,2} & \cdots & y^{1, F} \\
y^{2,1} & y^{2,2} & \cdots & y^{2, F} \\
\vdots & \vdots & \ddots & \vdots \\
y^{R, 1} & y^{R, 2} & \cdots & y^{R, F}
\end{array}\right] ; \quad x=\left[\begin{array}{c}
x^{1} \\
x^{2} \\
\vdots \\
x^{R}
\end{array}\right] ;
\end{gathered}
$$

in which $R$ denotes the total number of countries and $F$ the total number of final demand categories. The total final demand vector $(\boldsymbol{y})$ is the sum of the following five categories in this research: household consumption, government expenditure, capital formation and changes of inventory. Consequently, the MRIO framework can be written as:

$\boldsymbol{x}=(\boldsymbol{I}-\boldsymbol{A})^{-1} \boldsymbol{y}$

where $(\boldsymbol{I}-\boldsymbol{A})^{-1}$ is the Leontief inverse matrix which captures both direct and indirect economic inputs to satisfy one unit of final demand in monetary value; $\boldsymbol{I}$ is an identity matrix with ones on the main diagonal and zeros everywhere else.

To calculate the consumption-based GHG emissions, we extend the MRIO table with a vector of sectoral $\mathrm{CO}_{2}$ equivalent $\left(\mathrm{CO}_{2} \mathbf{e}\right)$ emission coefficients for all sectors in all regions, $\boldsymbol{k} . \mathrm{CO}_{2} \mathbf{e}$ translates all greenhouse gases into the amount of $\mathrm{CO}_{2}$ which would have the equivalent global warming impact. Thus, the total consumption-based GHG emissions for all regions can be calculated by:

$$
\mathrm{CO}_{2} \mathbf{e}=\boldsymbol{k}(\boldsymbol{I}-\boldsymbol{A})^{-1} \boldsymbol{y}+\mathbf{h h}_{\mathrm{dir}}
$$

where $\mathbf{C O}_{2} \mathbf{e}$ is the total GHG emissions associated with goods and services used for the final demand of all countries. Please note that Eq. (2) can be driven by an individual category of final demand to derive total sectoral outputs that are necessary for satisfying this given category of final demand. $\mathbf{h h}_{\mathbf{d i r}}$ is the household direct emissions.

In other words, we began with the MRIO technical coefficients matrix $\boldsymbol{A}$, which represents the entire input or production structure (as input-output relationships) of the global economy, and took the inverse of (I-A) (i.e., Leontief inverse matrix). Intuitively, this inverse matrix represents the infinite input layers needed for satisfying final consumption. Thus, when multiplying this inverse matrix with a household's consumption vector, we receive a total output vector accounting for all the direct and indirect inputs triggered throughout global supply chains by household's consumption. To account for GHG emissions at each stage of the supply chain, a vector of GHG coefficients (i.e., the amount of GHG emitted during the production of one unit of output for each sector) is multiplied with the total output vector.

In this study, we use the environmentally extended multi-regional input-output approach (MRIO) to estimate carbon footprints of different household groups in 90 developing countries from the World Bank's Global Consumption Database (The World Bank 2015), EU countries (EUROSTAT, 2016) and the USA (U.S. Bureau of Labor Statistics 2012). The global MRIO table is collected from the Eora database (http://worldmrio.com/). Eora is a multiregional input-output database that provides a time series of high-resolution input-output (IO) tables with matching environmental and social satellite accounts for 186 countries (Lenzen et al. 2012b, 2013). The MRIO tables from Eora contain trade flows, production, consumption and intermediate use of commodities and services for $26 \mathrm{sec}-$ tors, both within and between 186 countries. Eora also provides sectoral GHG emissions here presented in carbon dioxide equivalent, $\mathrm{CO}_{2} \mathbf{e}$, which allows comparison of various greenhouse gas emissions based upon their global warming potential. This study focuses on 2010 to accommodate the World Bank's Global Consumption Database. 
In the World Bank's Global Consumption Database, households in developing countries were categorized in four consumption segments: lowest, low, middle and higher. The lowest expenditure segment (i.e., daily expenditure below \$2.97 PPP per capita) corresponds to the bottom half of the global distribution, or the 50th percentile and below; the low-consumption segment (between \$2.97 PPP and \$8.44 PPP per capita a day) corresponds to the 51th-75th percentiles; the middle-consumption segment (between $\$ 8.44$ and $\$ 23.03$ PPP per capita a day) to the 76th-90th percentiles; and the higher-consumption segment (above \$23.03 PPP per capita a day) to the 91st percentile and above. PPP refers to purchasing power parities, which tells us how many dollars are needed to buy one dollar's worth of goods in a country as compared to the USA.

While the World Bank database classifies the expenditure groups using these dollar ranges, the EU and U.S. statistical offices use different percentiles. We aggregated the latter to quintiles. While the former is standardized in terms of consumption categories, the EU and U.S. statistical offices have different consumption categories and this requires separate bridging matrices when linking consumer expenditure categories to input-output sectors (for more detail, see Hubacek et al. 2017, which uses additional countries to the ones used in this paper).

\subsection{Current distribution of income and associated carbon emissions}

According to the World Bank's Global Consumption Database, half of the global population live on less than \$2.97(PPP) a day. The top $10 \%$ spend more than \$23 (PPP) per day. Clearly their lifestyles, expenditure patterns and associated per capita carbon footprints differ considerably (see Fig. 1). According to our calculations, the top $10 \%$ cause more than one-third of global GHG emissions, whereas the bottom $50 \%$ are responsible for only $15 \%$ of global emissions.

There are larger differences of carbon footprint between the poor and the rich. Our calculations show that the carbon footprint averages $1.6 \mathrm{t}$ per day for the lowest income category, then quickly increases to 4.9 and $9.8 \mathrm{t}$ for the two middle-income categories, and finally to an average of $17.9 \mathrm{t}$ for the highest income category. These numbers are based on household's consumption bundles and associated direct and indirect emissions, i.e., supply chain emissions associated with household final consumption, but not accounting for associated shares of public expenditure and infrastructure-related carbon emissions and thus slightly lower than in Hubacek et al. (2017). Nevertheless, the average carbon footprint of the global elites is about 11 times as high as the carbon footprint of the lowest

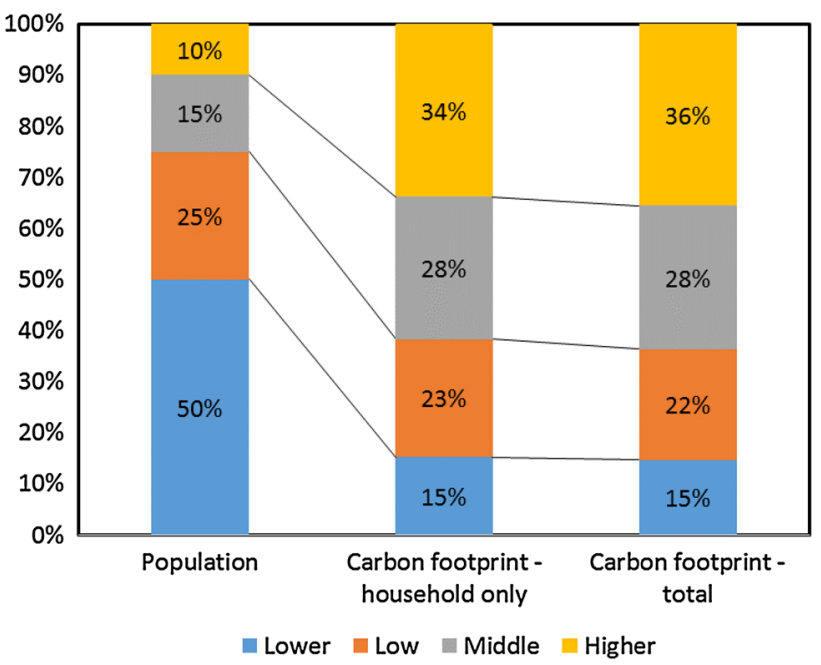

Fig. 1 Shares of population and associated carbon emissions. Note we used the World Bank Global Consumption Database for the calculation of per capita carbon footprint for the lowest, low- and middle-expenditure group. For per capita carbon footprint of higherexpenditure group, we used the average of per capita carbon footprint of the higher-expenditure group from the Global Consumption Database and the per capita carbon footprint of EU countries and the USA

expenditure group. When disaggregating the various groups further, to potentially account for the global top $1 \%$ and the extreme poor, these differences may become more pronounced. Unfortunately, data constraints prevent us from investigating this in great detail.

These differences between global expenditure groups hide potentially starker differences within countries in terms of expenditure patterns and associated carbon footprints, and this is especially true for poor countries with a majority of the population living in poverty. For example, according to the World Bank dataset, a number of countries, such as the Democratic Republic of Congo with $99 \%$ of the population, in Madagascar and Burundi 98\%, Tanzania 95\%, Mozambique 94\%, Niger 93 and in Nigeria $90 \%$, were situated in the lowest expenditure category in 2010.

In Fig. 2, we show per capita carbon footprints for each expenditure and income category, for each country in our dataset, graphed against GDP per capita. What is striking is the high level of carbon footprints of the middle- and highexpenditure categories of the developing countries, which are about the same range as the middle- and higher-income categories of the rich countries. This surprising result needs further investigation, but an important contributing factor is the low carbon efficiency of those countries paired with relatively low share of imports from more carbon-efficient countries. Their low average carbon footprints are mainly due to the large share of poor people, with very low footprints, in those countries. 


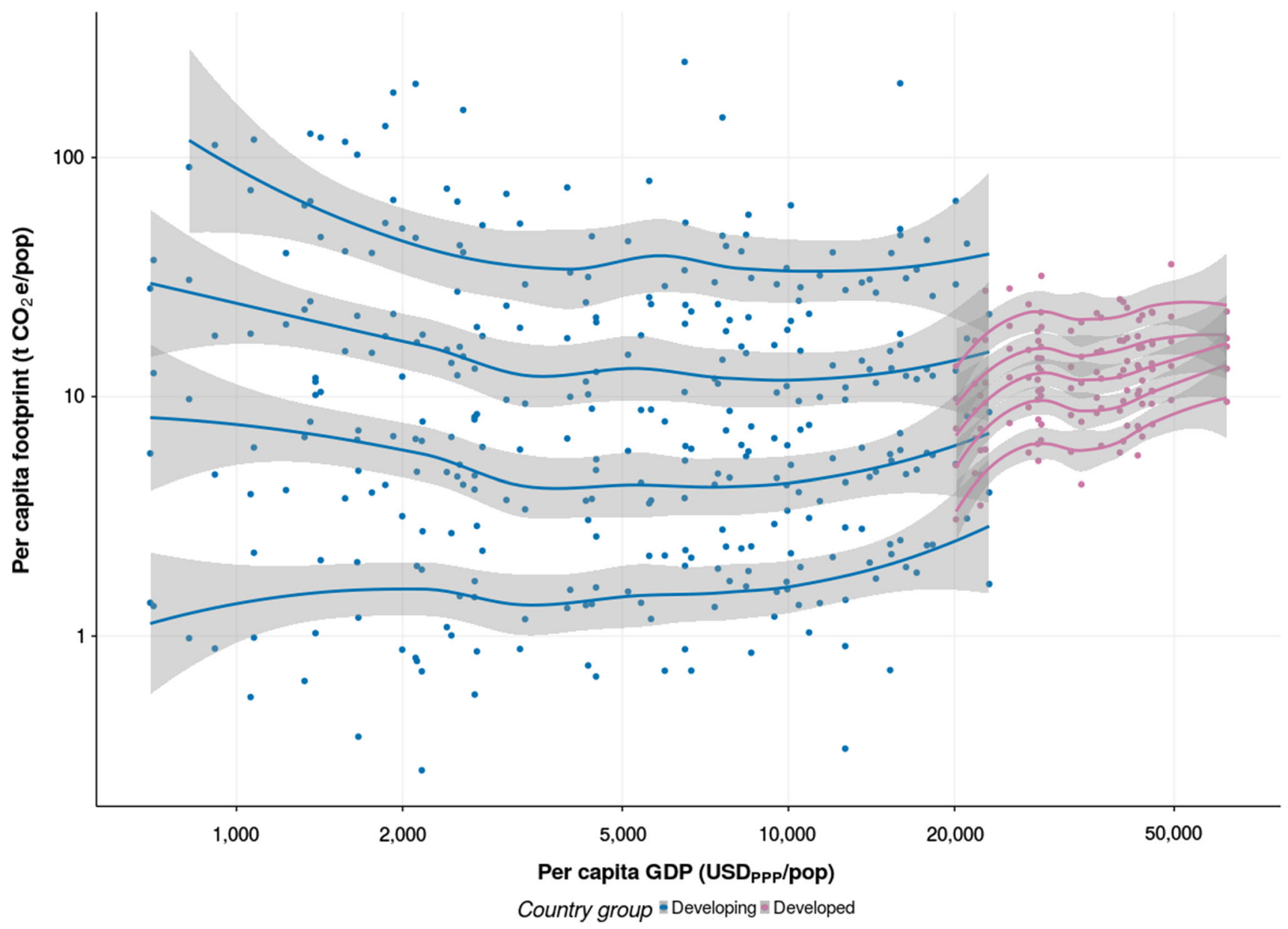

Fig. 2 Carbon footprint per income category. Notes carbon footprints (in tons per capita) per expenditure and income category, respectively, for 109 countries against per capita income. Blue dots are for

When exploring how carbon disparity changes with increasing income, we find that rich countries on the right show much less spread than the developing countries on the left. When regressing standard deviation versus income per capita, we see that the spread decreases with income for developing countries (see Table S1 in the Supporting Information; SI). On the other hand, developed countries show a $\mathrm{N}$-shaped relationship, if we exclude the last observation for Norway, between carbon inequality and income for all income categories. When looking at the two datasets combined, we observe some sort of opposite Kuznets curve for carbon inequality in that carbon inequality goes initially down with increasing income and then up.

\subsection{Carbon elasticity: measuring the carbon income nexus}

Carbon elasticity is a measurement of how responsive carbon emissions are to an increase in income. Figure 3 the developing country group provided by the World Bank and purple dots represent EU countries and the USA

shows the average per capita carbon footprint for each country and shows a positive correlation between per capita income and per capita carbon (see also Table S2 in the Supporting Information). Since the function is nonlinear, the elasticity will depend on the level of GDP per capita. Using the robust regression coefficients, a $1 \%$ increase in GDP per capita increases the average footprint by $0.36,0.61$ and $0.87 \%$ for an average GDP per capita of $1000,10,000$ and 100,000 USD, respectively.

Carbon elasticities are estimated regressing a log-log model of footprint per capita on income per capita approach for each country. Figure 4 shows the estimated elasticities, which are percentage increases in footprint from increases in income (proxied by expenditures per consumption segment) computed for each country (see also Tables S3 and S4 for regression results). For developing countries, there is a significant decrease in carbon elasticities as GDP increases (see Figure S1). A doubling of GDP per capita decreases elasticities by $4 \%$. For developed countries, the regression is not significant because of the 


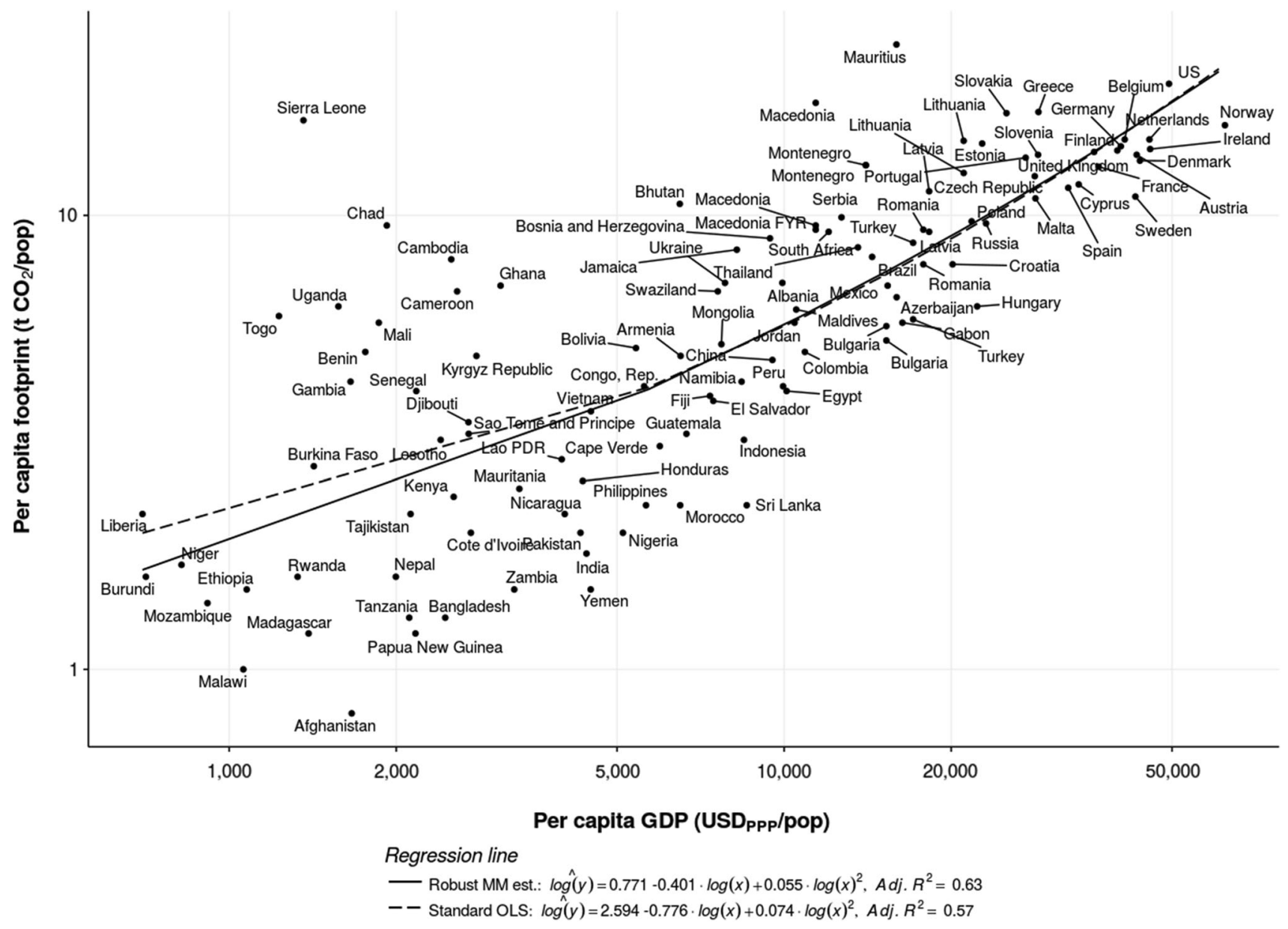

Fig. 3 Per capita carbon footprints versus per capita GDP in \$PPP. Note we did both OLS and robust MM regressions, due to the number of outliers. The robust regression corroborates the OLS results

small number of observations. The developing countries result is consistent with the literature (see, e.g., Liddle 2015).

\subsection{What about the elephant in the room?}

There are in fact two elephants in the room: China and India. Together they represent more than $36.5 \%$ of the global population, and their economies are growing quickly, although China's economic growth has slowed somewhat recently. Nevertheless, China's economy has been doubling on average every 7 years over the last 35 years. In other words, China's economy is now more than 30 times the size it was in 1980. At the same time, both countries have large segments of the population that still live in poverty. As of 2010, in China there were still more than 500 million people living with less than three dollars (PPP) a day. While we find a sizeable middle class in China, most people in India (more than 1 billion people) fall in the lowest expenditure category without any significant middle class or sizeable high-income earners (see Fig. 5).

Given the differences in the demographics of these two countries, it is not surprising to see that most of the carbon emissions in China are caused by its middle class (78\%) whereas in India it is the poorest category contributing 63\% to the carbon total. The elites contribute $9 \%$ in China and only about $0.5 \%$ in India. These differences are mainly due to the population size and associated consumption patterns in each category (Fig. 6).

The national average is fairly low for both countries with $4.8 \mathrm{t}$ in China and $1.7 \mathrm{t}$ for India (see dotted line in Fig. 7), but the variation between income groups is significant, ranging from an average of $1.2 \mathrm{t}$ for the lowest to close to $40 \mathrm{t}$ per capita in India and from $1.5 \mathrm{t}$ to about $30 \mathrm{t}$ in China. Striking is the difference in average carbon consumption of the elites with $29.5 \mathrm{t}$ in China and $39.9 \mathrm{t}$ in India. This is mainly due to a higher share of high carbonintensive consumption items of India's higher-expenditure class. 


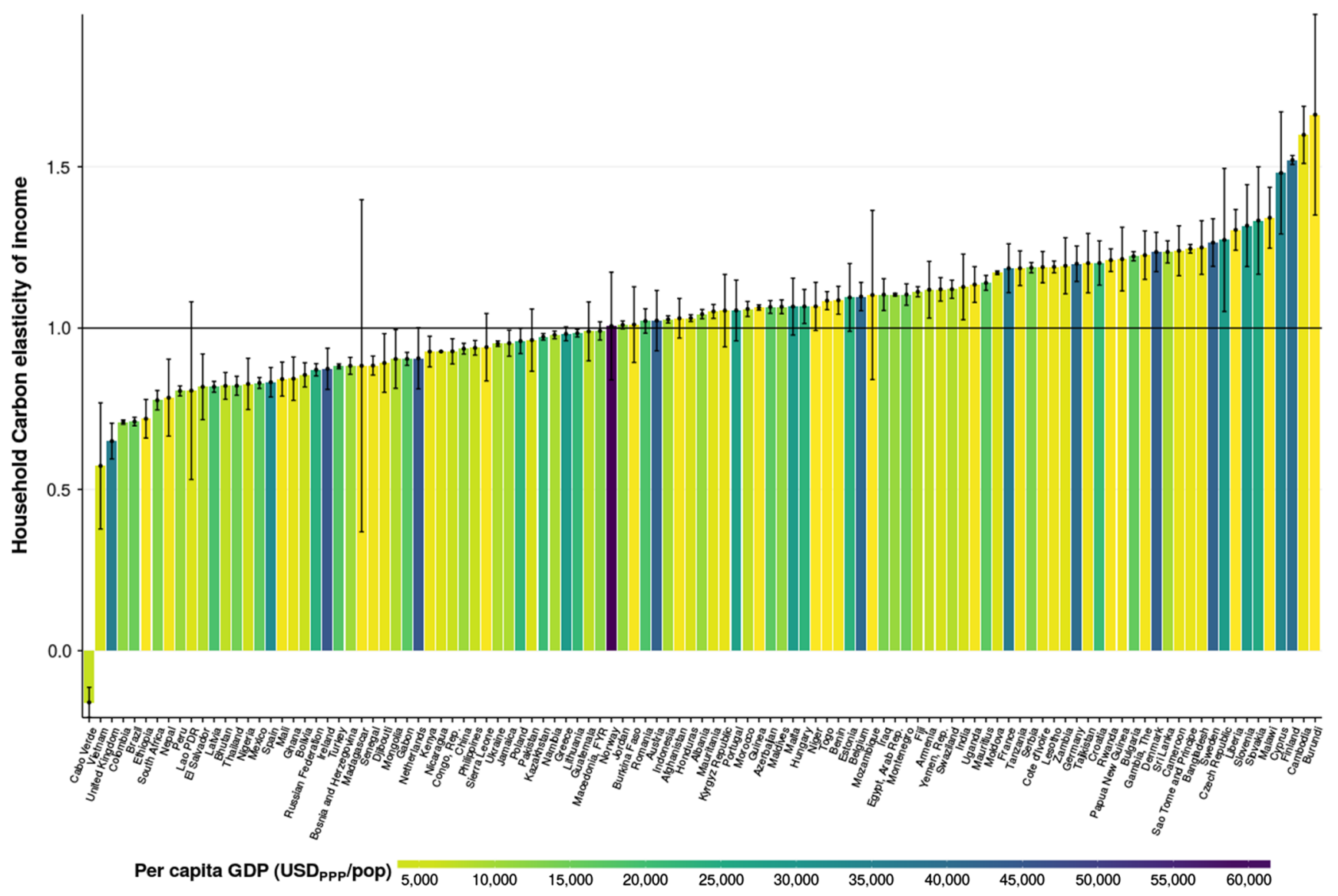

Fig. 4 Household carbon elasticity. Notes error bars are obtained from one standard error of the estimates

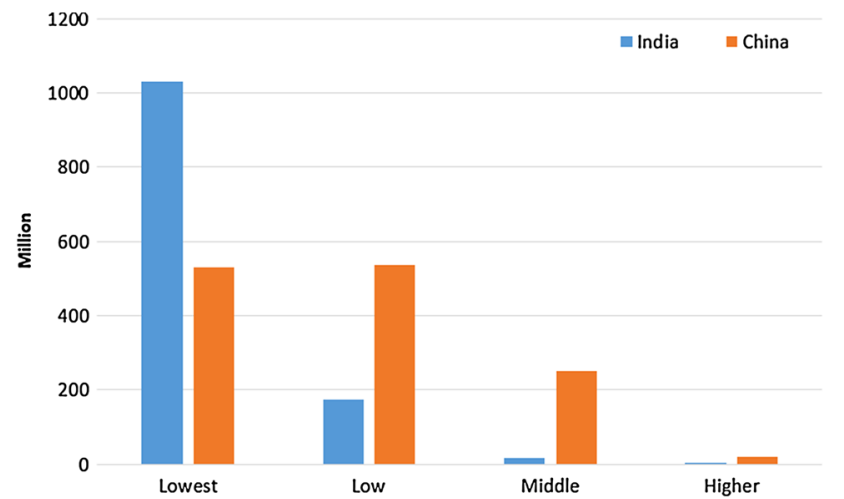

Fig. 5 Population in China and India per expenditure category

\subsection{Carbon implications of poverty alleviation}

The compiled dataset allows us to assess some important questions such as what are the carbon implications of moving the poorest people on the planet out of poverty. When looking specifically at India and China, we find that the global carbon emissions would increase by 7 and $4 \%$, respectively. The latter would be the equivalent to the total carbon emissions of Japan in 2012, and the increase in

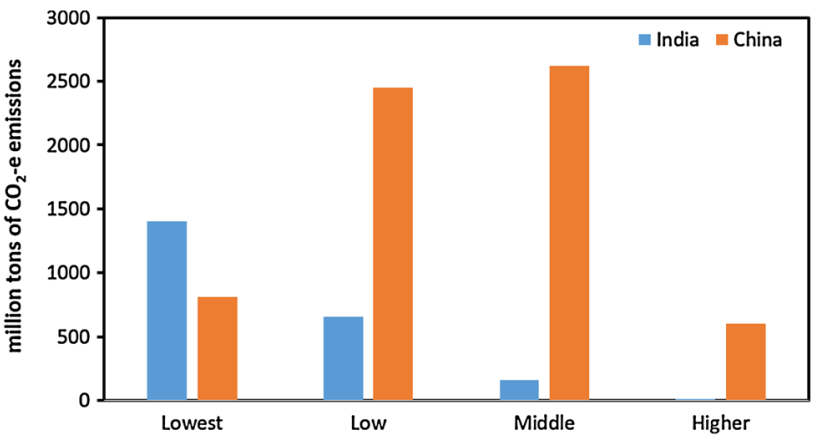

Fig. 6 Total carbon emissions (in million tons) in China and India for each expenditure category

emissions triggered through the poverty alleviation scenario in India is almost equal to the total carbon emissions of the EU in 2012.

We did a similar exercise at the global level by moving the lowest expenditure category (less of \$2.97 PPP) to the next consumption level ( $\$ 2.97$ to $\$ 8.44 \mathrm{PPP})$ by the year 2050. The IPCC reported that the remaining carbon emissions quota associated with a $66 \%$ of probability of keeping warming below $2{ }^{\circ} \mathrm{C}$ is estimated to be $1200 \mathrm{Gt} \mathrm{CO}_{2}$ (Friedlingstein et al. 2014). In this study, we compare this 
Fig. 7 Per capita carbon footprints (in tons) in India and China for each expenditure category

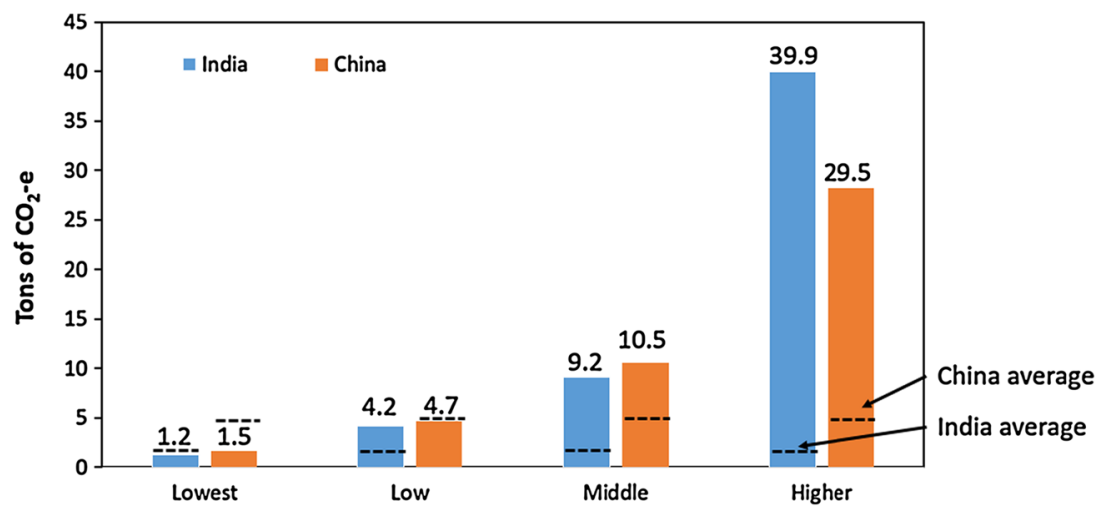

available carbon quota to the required carbon to lift the lowest household group or the lowest $50 \%$ of world population out of poverty (i.e., to the next income level), which constitutes a still fairly modest income in comparison to the income levels of developed countries. We found that by moving the global poor into the next income category we require $66 \%$ of available cumulative carbon emissions that are not available for other uses or need to be taken out of the atmosphere in order for the global community to remain on track toward achieving the climate target of staying within a $2{ }^{\circ} \mathrm{C}$ increase (for more details, see Hubacek et al. 2017).

\section{Conclusions}

Our results show that when focusing on countries and averages we miss a lot of interesting information and details on the environmental impacts of different income groups. Not only are there huge differences in carbon footprints between countries but we also find interesting differences within countries closely linked to differences in incomes between and within countries. When looking at poor countries, we tend to find larger disparities between the carbon footprints of the rich versus the poor reflecting larger income inequalities in those countries. For some very poor countries, the disparity is at more than one order of magnitude and seems to be larger than differences between higher and lower incomes in rich countries such as the USA and European countries. There seems to be some convergence of carbon footprints with increasing income within the developing countries. The flipside of the coin is the fact that the carbon footprint tends to increase with higher income. This is also reflected in the fact that the global elites, i.e., the top $10 \%$ of world population, are responsible for about $34 \%$ of household-related direct and indirect (i.e., supply chain-related) carbon emissions. Given the current context, increasing income leads to increasing carbon footprints and makes global targets for mitigating greenhouse gases more difficult to achieve given the pace of technological progress and current levels of fossil fuel dependence. Given other policy goals, especially poverty alleviation, a redistribution of carbon shares from the global elites to the global poor seems to be desirable; but a focus on efficiency gains and technological advances seemingly avoids other currently more unpopular policy options. Given the huge level of carbon inequality, critical discussion of undifferentiated income growth and current carbon-intensive lifestyles and consumption patterns need to enter the climate discourse to a larger extent.

Acknowledgements The content of this study had been presented at numerous conferences since June 2015 and benefited greatly from suggestions of the respective audiences and from the helpful comments from the anonymous referees of this journal. Klaus Hubacek's research was partly supported by the Czech Science Foundation under the project VEENEX (GA ČR no. 16-17978S). Kuishuang Feng acknowledges the support of the National Natural Science Foundation of China (71628301).

\section{References}

Baer P, Harte J, Haya B, Herzog AV, Holdren J, Hultman NE, Kammen DM, Norgaard RB, Raymond L (2000) Climate change: equity and greenhouse gas responsibility. Science 289(5488):2287

Baumert KA, Herzog T, Pershing J (2005) Navigating the numbers: greenhouse gas data and international climate policy. World Resources Institute, Washington

Davis S, Peters G, Caldeira K (2011) The supply chain of $\mathrm{CO}_{2}$ emissions. Proc Natl Acad Sci 108(45):18554-18559

Eurostat (2016) Structure of consumption expenditure by income quintile. Statistical Office of the European Communities, Luxembourg

Feng KA, Chapagain S, Pfister S, Hubacek K (2011) Comparison of bottom-up and top-down approaches to calculating the water footprints of nations. Econ Syst Res 23(4):371-385

Friedlingstein P, Andrew RM, Rogelj J, Peters GP, Canadell JG, Knutti R, Luderer G, Raupach MR, Schaeffer M, van Vuuren DP, Le Quere C (2014) Persistent growth of $\mathrm{CO}_{2}$ emissions and implications for reaching climate targets. Nat Geosci 7(10):709-715

Hardoon D (2015) Wealth: having it all and wanting more. Oxfam Wealth, Oxford 
Hubacek K, Baiocchi G, Feng K, Padwardhan A (2017) Poverty eradication in a carbon constrained world. Nat Commun (in press)

Lenzen M, Moran D, Kanemoto K, Foran B, Lobefaro L, Geschke A (2012a) International trade drives biodiversity threats in developing nations. Nature 486(7401):109-112

Lenzen M, Kanemoto K, Moran D, Geschke A (2012b) Mapping the structure of the world economy. Environ Sci Technol 46(15):8374-8381

Lenzen M, Moran D, Kanemoto K, Geschke A (2013) Buiding Eora: a global multi-regional input-output database at high country and sector resolution. Econ Syst Res 25(1):20-49

Liddle B (2015) What are the carbon emissions elasticities for income and population? Bridging STIRPAT and EKC via robust heterogeneous panel estimates. Glob Environ Change 31:62-73

Motesharrei S, Rivas J, Kalnay E, Asrar G, Busalacchi A, Cahalan R, Cane MA, Colwell R, Feng K, Franklin R, Hubacek K, MirallesWilhelm F, Miyoshi T, Ruth M, Sagdeev R, Shirmohammadi A, Shukla J, Srebric J, Yakovenko V, Zeng N (2016) Population, inequality, and resource-use: modeling sustainability requires bidirectional coupling of the earth and human systems. Natl Sci Rev 3:470-494

Peters GP, Andrew R, Lennox J (2011) Constructing an environmentally extended multi-regional input-output table using the GTAP database. Econ Syst Res 23(2):131-152

Prell C, Feng K (2016) The evolution of global trade and impacts on countries' carbon trade imbalances. Soc Netw 46:87-100

Prell C, Feng K, Sun L, Geores M, Hubacek K (2014) The economic gains and environmental losses of US consumption: a worldsystems and input-output approach. Soc Forces 93(1):405-428

Raupach MR, Davis SJ, Peters GP, Andrew RM, Canadell JG, Ciais P, Friedlingstein P, Jotzo F, van Vuuren DP, Le Quéré C (2014) Sharing a quota on cumulative carbon emissions. Nat Clim Change 4:873-879

Steckel JC, Brecha RJ, Jakob M, Strefler J, Luderer G (2013) Development without energy? Assessing future scenarios of energy consumption in developing countries. Ecol Econ 90:53-67
The Sustainable Development Solutions Network (2014) Agenda for sustainable development. Report for the UN Secretary General. Paris, France and New York, USA. http://unsdsn.org/resources

The World Bank (2015) Global consumption database. The World Bank, Washington. http://datatopics.worldbank.org/consump tion/. Accessed 23, Feb 2017

UNFCCC (2015) Historic Paris Agreement on Climate Change-195 nations set path to keep temperature rise well below 2 degrees Celsius. United Nations Framework Convention on Climate Change, Bonn

United Nations (1972) Report of the United Nations conference on the human environment, Stockholm, 5-16 June 1972 (A/ CONF.48/14/Rev.1)

United Nations (1992) Report of the United Nations conference on environment and development, Rio de Janeiro, 3-14 June 1992, vol 1, Resolutions adopted by the conference (United Nations publication, Sales No. E.93.I.8 and corrigendum)

United Nations (2002) Report of the world summit on sustainable development, Johannesburg, South Africa, 26 August-4 September 2002. (United Nations publication, Sales No. E.03.II.A.1 and corrigendum)

United Nations (2012) Future we want. Resolution adopted by the general assembly on 27 July 2012. A/RES/66/288. Annex

United Nations (2015) Transforming our world: the 2030 agenda for sustainable development. Resolution adopted by the general assembly on 25 September 2015. A/RES/70/1

U.S. Bureau of Labor Statistics (2012) Consumer expenditure survey. U.S. Bureau of Labor Statistics, Washington

Weinzettel J, Hertwich EG, Peters GP, Steen-Olsen K, Galli A (2013) Affluence drives the global displacement of land use. Glob Environ Change 23(2):433-438

Wiedmann T (2009) A review of recent multi-region input-output models used for consumption-based emission and resource accounting. Ecol Econ 69(2):211-222

World Commission on Environment and Development (1987) Our common future. Oxford University Press, Oxford

Yu Y, Hubacek K, Feng K (2013) Tele-connecting local consumption to global land use. Glob Environ Change 23(5):1178-1186 